\title{
The Contribution of Learning by Modeling (LbM) to Students' Understanding of Complexity Concepts
}

\author{
Kamel Hashem and David Mioduser
}

\begin{abstract}
This paper describes part of a project about Learning-by-Modeling (LbM). The ideas of complexity are increasingly becoming an integral part in understanding natural and social sciences. Previous research indicates that involvement with modeling scientific phenomena and complex systems can play a powerful role in science learning. Some researchers argue with this view indicating that models and modeling do not contribute to understanding complexity concepts, since these increases the cognitive load on students. This study investigates the effect of different modes of involvement in exploring scientific phenomena using a computer agent-based modeling tool, on students' understanding of complexity concepts. Quantitative and qualitative methods are used to report about 121 freshmen students that engaged in participatory simulations about complex phenomena, showing emergent, self organized and decentralized patterns. Results show that LbM plays a major role in students' concept formation about complexity concepts.
\end{abstract}

Index Terms-Agent Based Modeling, Complex Systems, Learning by Modeling, Mental Models.

\section{INTRODUCTION}

Understanding the behavior of complex systems has become a focal issue for scientists in a wide range of disciplines. For the last century, substantial theoretical developments led to a shift in perspective allowing scientists to study phenomena and processes in the world focusing on aspects, interrelationships and processes that were overlooked by traditional Science. In the last decades, the basic paradigm of the novel approach has evolved into several theoretical and methodological branches, e.g., Cybernetics [1]; General Systems Theory [2]; System Dynamics [3]; Chaos Theory [4]; Complexity [4]. The impressive theoretical apparatus, complemented with the development of sophisticated computer tools, is nowadays a powerful means used by scientists to "dive into complexity" [5].

The inquiry about phenomena in the world adopting a systemic perspective is a challenging intellectual enterprise for scientists and students of science as well [6]. Learning about concepts in complex systems is greatly aided by interactive simulations and models. Research indicates that learning through observation do not necessarily lead to

Manuscript received June 8, 2011; Revised June 15, 2011.

Kamel Hashem is with the Department of Learning Sciences, School of Educational Sciences, Al-Quds University, Jerusalem, Palestine. (phone: 972-522-292996; fax: 972-265-64511; e-mail: hashemk@alquds.edu).

Prof. David Mioduser is with the Department of Education in Math Science and Technology, School of Education, Tel-Aviv University, Tel-Aviv, Israel. (e-mail: miodu@post.tau.ac.il). strong intuitions or deep understanding of systems [18]. For example people observed bird flocks for thousands of years before anyone suggested that flocks are leader-less, and people participate in traffic jams without much understanding of what cause the jams, such phenomena may be regarded as complex systems. Observation and participation are not enough; people need a richer sense of involvement with systems in order to understand them [5], [9], [10], [14], [16], [21]. Modeling can provide students with the power to understand and explore systems that were previously difficult to trace and predict their behavior, new techniques that help to learn important concepts on complex systems, to generate relevant questions, theories and hypothesis about phenomena, and to build and run models related to their theories [7], [12], [15], [19], [20].

Despite the utilization of new learning approaches with models, students experience difficulties in learning concepts relevant to understanding complex systems currently taught in existing science courses - student thinking may be counter-intuitive or might conflict with the scientific models, and the learning ideas concerning emergence or stochastic processes are difficult because of difference with teleological beliefs, where students tend to think of systems having centralized control [8], [13], [14], [20]. Hmelo-Silver and Pfeffer (2004) argue that the characteristics of complex systems make them difficult to understand, since they are comprised of multiple levels of organization that often depend on local interactions (the causes and effects are not obviously related); also it requires that students should construct a network of concepts and principles about the phenomena with complexity and their interrelationships [14], [17], [20]. Some researchers argue that modeling did not contribute a lot in understanding complexity since it increases the cognitive load on students (see [11]).

This study focused on the effect of different modes of involvement in exploring a scientific phenomena using computer modeling tools, on students' understanding of complexity: from simple observation, through different stages of intervention and manipulation. It is part of a more comprehensive study pursuing the goals: (1) to study the role of modeling in the learning process of complexity and complex systems in the natural and artificial worlds; (2) to examine the contribution of different modes of involvement in the modeling process (e.g., observation and explanation, intervention and manipulation, programming and development) to the students' understanding of complexity; (3) to examine the effect of the level of complexity and properties (e.g., emergence, self-organized ...) of the systems being manipulated on the student's learning; and (4) to study the evolution in time of the students' mental models of 
complexity as a function of the different variables (e.g., under study. modes of involvement; level of complexity) of the system

TABLE 1. CATEGORIZATION OF CONCEPTS RELATED UNDERSTANDING COMPLEX SySTEMS

\begin{tabular}{|c|c|c|}
\hline Parameters & Clockwork component coding & Complexity component coding \\
\hline $\begin{array}{l}\text { Emergence } \\
\text { Does a pattern emerging? } \\
\text { Is there a difference between agents and } \\
\text { system? } \\
\text { Is there movement of the agents within the } \\
\text { system? }\end{array}$ & $\begin{array}{l}\text { Agents act in isolation. } \\
\text { Simple stepwise description. } \\
\text { Explicit description of non-changing } \\
\text { system. }\end{array}$ & $\begin{array}{l}\text { Local interaction between agents. } \\
\text { System structure exhibits a more stable behavior, } \\
\text { yet all agents have the potential to be replaced by } \\
\text { other similar independently operating agents. } \\
\text { Identification of pattern formation as the agents } \\
\text { come together to form a system. }\end{array}$ \\
\hline $\begin{array}{l}\text { Self-organization } \\
\text { Are there feedback loops within the } \\
\text { system? Do they affect the outcome? } \\
\text { How do agents behave before they are part } \\
\text { of the system? }\end{array}$ & $\begin{array}{l}\text { Small causes cause small effects, large } \\
\text { causes cause large effects. } \\
\text { Effects are functions of causes } \\
\text { There is no randomness or chance in } \\
\text { agents' action. } \\
\text { One thing leads to another. } \\
\text { Agents' actions are predictable. }\end{array}$ & $\begin{array}{l}\text { Small causes can produce large effects. } \\
\text { System organizes itself based on the interactions of } \\
\text { the agents, structure is never certain. } \\
\text { Despite agent's movements, the system persists in a } \\
\text { self-organization fashion. } \\
\text { Effects are not straightforward functions of causes. }\end{array}$ \\
\hline $\begin{array}{l}\text { Decentralization } \\
\text { How systems are governed? } \\
\text { What initiates the formation of the system? }\end{array}$ & $\begin{array}{l}\text { Central control and deterministic single } \\
\text { causality. } \\
\text { Control/order is external. }\end{array}$ & $\begin{array}{l}\text { Agent's actions are independent of each other, } \\
\text { despite that they all operate under the same rules. }\end{array}$ \\
\hline
\end{tabular}

\section{METHOD}

\section{A. Subjects}

Participants are 121 undergraduate students (ages ranging from 18 to 20 years old) from the science department at Al-Quds University in Jerusalem, divided into four groups by the kind of involvement in working with models: observation, exploration, manipulation, and model-development modes.

The students were selected based on their scientific background, all have done the tawjehi exam as required by the ministry of education for the scientific track, and they are all studying first year compulsory science courses in the faculty of science.

\section{B. Research Instruments}

(1)The learning environment comprising two components:

- Net Logo, a specialized program developed at Northwestern University for agent-based modeling and for learning and understanding complex systems [20].

- Tasks and activities in which students run NetLogo models and are requested to perform tasks with the models.

(2) Data collection tools included:

- Pre-test comprising general background and demographic information (e.g., major area, gender) and four questions dealing with complexity concepts such as emergence, self-organization and decentralization.

- Structured observation and data forms.

- "Mental model worksheet" focusing on students' complex-system-mental-model (CSMM), completed by the end of each activity.

- Structured interview, focusing on students' understanding and reasoning about emergence,

- Self-organization and decentralization.

\section{Procedure}

All students attended a two hours introduction lesson to the Net Logo environment.

The study was carried in four stages:

(1) Pre-test.

(2) Treatment in four different modes.

- Observation group: in 2 sessions of 90-minutes students were introduced to two models (two levels of complexity), requested to observe agents interactions, and to complete the CSMM worksheet.

- Exploration group: in 2 sessions of 90-minutes students were introduced to two models (two levels of complexity), were given an initial set of conditions for the system followed by a final set of conditions in which one or two parameters were changed (e.g., change in a variable-slider or a switch) while the others remained constant. After each model students were interviewed and requested to complete the worksheet.

- Manipulation group: in 2 sessions of 90-minutes students were introduced to two models (two levels of complexity) using NetLogo. They were asked about how the system would change if the system variables were altered, and even allowed to use NetLogo commands. The students then manipulated the system variables according to the interviewer's questions, explained their observations of the system's behavior and compared these with their initial predictions. After each model students completed the worksheet.

- Development and Design group: students were introduced to the Netlogo programming environment (48 hours), in order to have the ability to construct the learning models. After each model students were asked to complete the worksheet.

(3) Interview after treatment: students were interviewed for their CSMM; all responses were video/audio taped. 
(4) Post-test: (same as pre-test).

\section{Scoring}

The coding scheme was based on the categorization defined by Jacobson (2001) [8], shown in Table 1. Students' answers were coded as non-reductive if these referred to a complexity-related matter (i.e. the whole is greater than the parts). Otherwise, if there was evidence of a stepwise approach to the explanation, the answer was coded as reductive (i.e. agents act in isolation). Jacobson (2001) refer to the reductive way of thinking as "deterministic and clockwork order".

\section{RESULTS}

\section{A. Quantitative Analysis}

Student's responses were coded in terms of the various types of component beliefs reflected in the answers (Table 3).

\begin{tabular}{|lccccc|}
\hline \multicolumn{5}{|c|}{ TABLE 2. STUDENT'S UNDERSTANDING COMPLEX SYSTEM } \\
\hline \multicolumn{5}{|c|}{ *Significance at $\alpha 0.01$} \\
\hline Group & $(\mathrm{N})$ & $\mathrm{M}$ & $\mathrm{SD}$ & $\mathrm{M}$ & $\mathrm{SD}$ \\
\hline Observation & 29 & 7.72 & 1.98 & $8.52^{*}$ & 2.58 \\
\hline Exploration & 33 & 7.15 & 1.95 & $7.85^{*}$ & 1.97 \\
\hline Manipulation & 28 & 7.5 & 1.64 & $8.57 *$ & 2.43 \\
\hline Development & 31 & 7.68 & 1.74 & $9.42 *$ & 2.35 \\
\hline
\end{tabular}

The results in Table 2 and Fig. 1 show that there is an increase in students' understanding of complexity concepts in all four groups (observation, exploration, manipulation, and development and design). Significant difference was observed (paired-samples t test) between the pre-test and post-test.

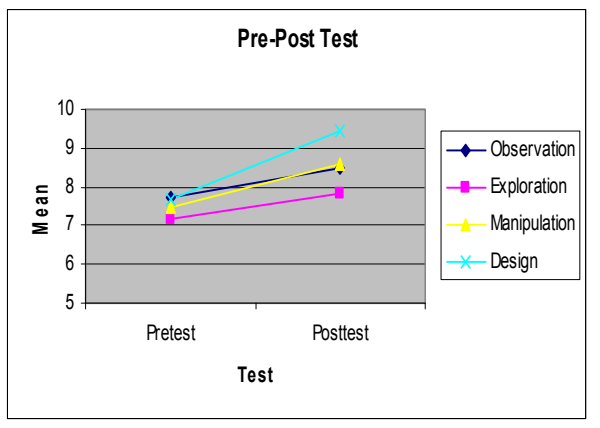

Fig. 1 - Students' understanding complex system

Understanding of complexity concepts (Emergence, Self-organization and Decentralization) is shown in Table 3. As expected, students in the development and design group identified more complexity concepts than the other groups. A general log-linear analysis was conducted to examine the differences between the groups in their perception of the concepts, showing significant relationship between the modes of involvement and understanding complexity concepts $(\chi 2(\mathrm{df}=25)=137.643, \mathrm{p}<.001)$. Concerning the tasks complexity level (complicated vs. complex models) results showed significant relationship between the different modes of involvement and understanding complexity concepts for the complicated model $(\chi 2(\mathrm{df}=25)=85.216, \mathrm{p}$ $<.001)$ and for the complex model $(\chi 2(\mathrm{df}=25)=120.128, \mathrm{p}$ $<.001)$.

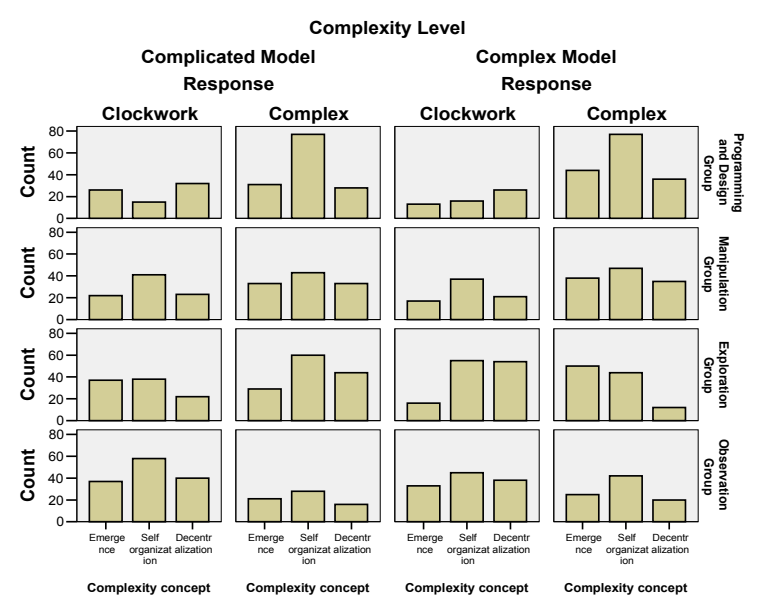

Fig. 2. Students' responses when understanding systems with the different complexity concepts and levels for the different modes of involvement

Table 3 and Fig. 2 present the frequencies and percentages of the students' responses on the different complexity concepts (emergence, self-organization and decentralization) for the four groups (observation, exploration, manipulation and design) with different levels of complexity. Chi-square tests were done to check these frequencies for significance, results show a significant relationship between the different modes of involvement and the different complexity concepts as follows: (a) Students largely favor to choose the clockwork model when they were asked questions regarding emergence $\left(\chi^{2}(\mathrm{df}=3)=20.841, \mathrm{p}<.001\right)$, in examining the observed cell frequencies from Table 3 ; it shows that that the observation group got the highest frequency $(60 \%)$ in favoring the clockwork model, on the other hand the design group showed high response in choosing the complex model on emergence $(66 \%)$ followed by the manipulation group $(65 \%)$ followed by the exploration group $(60 \%)$ and finally the observation group (40\%), (b) Students largely favor to choose the clockwork model when they were asked questions regarding self-organization $(\chi 2(\mathrm{df}=3)=73.683, \mathrm{p}<.001)$, in examining the observed cell frequencies from Table 3 ; the observation group showed the highest frequency (67\%) in favoring the clockwork model, on the other hand the design group showed high response in choosing the complex model on self-organization ( $83 \%$ ) followed by the manipulation group (54\%) followed by the exploration group (53\%) and finally the observation group (32\%), and (c) Students largely favor to choose the clockwork model when they were asked questions regarding decentralization $(\chi 2(\mathrm{df}=3)=21.906, \mathrm{p}$ $<.001$ ), in examining the observed cell frequencies from Table 3; the observation group showed the highest frequency $(68 \%)$ in favoring the clockwork model followed by the manipulation group (54\%) followed by the exploration group $(58 \%)$ followed by the design group (48\%) and finally the manipulation group (39\%), on the other hand the manipulation group showed high response in choosing the complex model on decentralization (61\%). 


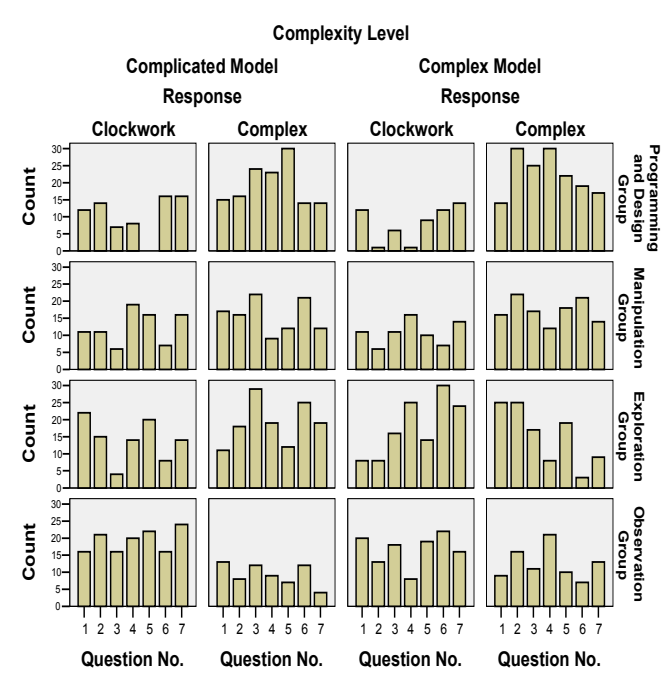

Fig. 3. Students' responses when understanding systems with different complexity levels for the different modes of involvement

Table 4 and Fig. 3 present the frequencies and percentages of the students' responses on the different types of questions given during the activities for the four groups (observation, exploration, manipulation and design). A chi-square test were done to check these frequencies for significance, Thus it can be concluded that there are significant differences in the frequency on the types of questions regarding understanding complexity concepts for the different types of involvement, and the results show that: (a) Students largely in favor to choose the clockwork model when they were asked about the difference between agents and systems $\left(\chi^{2}(\mathrm{df}=3)=16.7, \mathrm{p}<\right.$ 0.01 ), in examining the observed cell frequencies from Table 4 ; it shows that the observation group got the highest frequency $(58.6 \%)$ in favoring the clockwork model, on the other hand it can be concluded that the design group showed high response in choosing the complex model on the same question (74.2\%) followed by the manipulation group (67.9\%) followed by the exploration group (65.2\%) and finally the observation group (41.4\%), (b) Students largely in favor to choose the clockwork model when they were asked about the agents behavior $\left(\chi^{2}(\mathrm{df}=3)=21.8, \mathrm{p}<0.01\right)$, in examining the observed cell frequencies from Table 4 it shows that the observation group got the highest frequency $(58.6 \%)$ in favoring the clockwork model, on the other hand it can be concluded that the design group showed high response in choosing the complex model on the same question $(79 \%)$ followed by the manipulation group and the exploration group (69.6\%) and finally the observation group (39.7\%), (c) Students largely in favor to choose the complex model when they were asked about the internal and environmental feedback loops $\left(\chi^{2}(\mathrm{df}=3)=35.6, \mathrm{p}<0.01\right)$, and $\left(\chi^{2}(\mathrm{df}=3)=39.3, \mathrm{p}<0.01\right)$ respectively, in examining the observed cell frequencies from Table 4 it can be concluded that for the internal feedback loops the design group showed high response in choosing the complex model (85.5\%) followed by the observation group (51.7\%) followed by the exploration group $(40.9 \%)$ and finally the manipulation group (38\%), and for the internal feedback loops the design group showed high response in choosing the complex model (83.9\%) followed by the manipulation group $(53.6 \%)$ followed by the exploration group (47\%) and finally the observation group (29.3\%), (d) Students largely in favor to choose the complex model when they were asked about the way that systems are governed $\left(\chi^{2}(\mathrm{df}=3)=22.2, \mathrm{p}<0.01\right)$, in examining the observed cell frequencies from Table 4 it can be concluded that the manipulation group showed high understanding for the complexity concepts $(75 \%)$ followed by the design group (53.2\%) followed by the exploration group (42.4\%) and finally the observation group (32.8\%).

TABle 3. Students' Frequencies and Percentages on Complexity Concepts to All Groups With Different LeVels of CompleXity (CD: COMPLICATED AND CX: COMPLEX; ** $\mathrm{P}<0.01)$

\begin{tabular}{|c|c|c|c|c|c|c|c|c|c|c|c|}
\hline \multirow[b]{3}{*}{ Group } & \multirow[b]{3}{*}{ Model } & \multirow[b]{3}{*}{$(\mathrm{N})$} & \multicolumn{3}{|c|}{ Emergence** } & \multicolumn{3}{|c|}{ Self-organization** } & \multicolumn{3}{|c|}{ Decentralization** } \\
\hline & & & \multicolumn{3}{|c|}{ Complexity Level Frq (\%) } & \multicolumn{3}{|c|}{ Complexity Level Frq (\%) } & \multicolumn{3}{|c|}{ Complexity Level Frq (\%) } \\
\hline & & & $\mathrm{CD}$ & $\mathrm{CX}^{* *}$ & Total** & $\mathrm{CD}^{* *}$ & $\mathrm{CX}^{* *}$ & Total** & $\mathrm{CD}^{* *}$ & $\mathrm{CX}^{* *}$ & Total** \\
\hline \multirow{2}{*}{ Observation } & Clockwork & 29 & $37(64)$ & $33(57)$ & $70(60)$ & $58(67)$ & $45(52)$ & $103(67)$ & $40(69)$ & $38(66)$ & $78(68)$ \\
\hline & Complex & 29 & $21(36)$ & $25(43)$ & $46(40)$ & $28(32)$ & $42(48)$ & $70(32)$ & $16(28)$ & $20(34)$ & $36(32)$ \\
\hline \multirow{2}{*}{ Exploration } & Clockwork & 33 & $37(56)$ & $16(24)$ & $53(40)$ & $38(38)$ & $55(56)$ & $93(47)$ & $22(33)$ & $54(82)$ & $76(58)$ \\
\hline & Complex & 33 & $29(44)$ & $50(76)$ & $79(60)$ & $60(61)$ & $44(44)$ & $104(53)$ & $44(67)$ & $12(18)$ & $56(42)$ \\
\hline \multirow{2}{*}{ Manipulation } & Clockwork & 28 & $22(39)$ & $17(30)$ & $39(35)$ & $41(49)$ & $37(44)$ & $78(46)$ & $23(41)$ & $21(38)$ & $44(39)$ \\
\hline & Complex & 28 & $33(59)$ & $38(68)$ & $71(65)$ & $43(51)$ & $47(56)$ & $90(54)$ & $33(59)$ & $35(63)$ & $68(61)$ \\
\hline \multirow{2}{*}{ Design } & Clockwork & 31 & $26(42)$ & $13(21)$ & $39(34)$ & $15(16)$ & $16(17)$ & $31(17)$ & $32(52)$ & $26(42)$ & $58(48)$ \\
\hline & Complex & 31 & $31(50)$ & $44(71)$ & $75(66)$ & $77(83)$ & $77(83)$ & $154(83)$ & $28(45)$ & $36(58)$ & $64(52)$ \\
\hline
\end{tabular}

\section{B. Qualitative analysis}

An examination of students' responses indicated additional qualitative differences between the different groups. A descriptive analysis of students' responses provided that also illustrates the coding procedure. Here is a portion of the answer given by one of the undergraduate students, Salem (all names have been changed) to the question: "How traffic jams occur? "

Salem: "First of all you might have an accident in the road or the road is not good to let drivers pass in a regular way..."

Interviewer: "ok, suppose we have no accidents and the 
road is good, is there any chance to a have a traffic jam?"

Salem: "Yes, let's say if we have a traffic light..."

In this answer, the student's response has been coded as 'reductive or clockwork' because it referred to a centralized control and deterministic single causality (i.e. the references to 'accidents, road is not good, and traffic light').

\section{CONCLUSIONS}

Understanding complex systems is the basis for much inquiry in science education. This article reports on a study about the interaction between modes of learning with an agent-based modeling tool and the understanding of complexity concepts. The implementation of such an instructional approach in the curriculum would have many benefits for learners, such as interdisciplinary learning allowing to see common patterns across traditionally separate fields, new ways of thinking (systems thinking and decentralized thinking), exploration of tools to think with, and construction of models linking between local causes and global behavior.

By introducing this new perspective (LbM) using agent based modeling for learning complexity and emergent phenomena, science learning will be more motivational and truthful, more inclusive and accessible to the great majority of students.

In addition, this study's results have clear implications for the design of learning environments that can support learning about complex systems.

\section{REFERENCES}

[1] Heims, S. (1991). The Cybernetics Group. Cambridge, MA: MIT Press.

[2] Von Bertalanffy, L. (1972). The History and Status of General Systems Theory. The Academy of Management Journal, 15(4), 407-426

[3] Forrester, J. (1971). World Dynamics. Cambridge, MA: Wright-Allen Press

[4] Simon, H. (1996). The Sciences of the Artificial ( $3^{\text {rd }}$ edition). Cambridge, MA: M.I.T. Press.
[5] Resnick, M., and Wilensky, U. (1998). Diving into Complexity: Developing probabilistic decentralized thinking through role-playing activities. Journal of Learning Sciences, 7 (2), 153-172.

[6] Chen, D., and Stroup, W. (1993). General system theory: Toward a conceptual framework for science and technology education for all. Journal of Science Education and Technology, 2(3), 447-459.

[7] Blikstein, P., and Wilensky, U. (2005). Less is more: agent-based simulation as a powerful learning tool in materials science. Proceedings of the IV International Joint Conference on AAMAS, Utrecht, Holland.

[8] Chi, M. T. H. (2005). Commonsense conceptions of emergent processes: why some misconceptions are robust? The Journal of the Learning Sciences, 14(2), 161-199.

[9] Gilbert, K. J., and Boulter, J. C. (Eds.). (2000). Developing models in science education. Dordrecht, Holland: Kluwer Academic Publishers.

[10] Gobert, D. J., and Buckley C. B. (2000). Introduction to model-based teaching and learning in science education. International Journal of Science Education, 22(9), 891-894.25

[11] Gobert, J. (2003). Harnessing technology to support on-line model building and peer collaboration.

[12] Hashem, K., and Mioduser, D. (2010). Learning by Modeling (LbM): The contribution of computer modeling to students' evolving understanding complexity. The $2^{\text {nd }}$ International Conference on Education Technology and Computer - ICETC 2010.

[13] Jacobson, M. J. (2001). Problem solving, cognition, and complex systems: Differences between experts and novices. Complexity, 6(3), 41-49.

[14] Jacobson, M., and Wilensky, U. (2006). Complex systems in education: scientific and educational importance and implications for the learning sciences. Journal of the Learning Sciences, 15(1), 11-34.

[15] Levy, S., and Wilensky, U. (2005). An analysis of student patterns of exploration with NetLogo models embedded in the connected chemistry environment. Proceedings of the annual meeting of the American Educational Research Association. Montreal, CA.

[16] Louca, L., and Constantinou, C. (2003). The use of computer-based microworlds for developing modeling skills in physical science: an example from light. International Journal of Science Education.

[17] Resnick, M. (1994). Changing the centralized mind. Cambridge, MA: MIT press.

[18] Resnick, M. (1996). Beyond the centralized mindset. Journal of the Learning Sciences, 5(1), 1-22.

[19] Stieff, M., and Wilensky, U. (2003). Connected chemistry-incorporating interactive simulations into the chemistry classroom. Journal of Science Education and Technology, 12(3), 285-302

[20] Wilensky, U., and Resnick, M. (1999). Thinking in levels: A dynamic systems approach to making sense of the world. Journal of Science Education and Technology, 8(1), 3-19.74

[21] Yehezkel, C.; Ben-Ari, M., and Dreyfus, T. (2005). Computer architecture and mental models. $A C M, 101-105$. 